\title{
The Identification of Fishing Ground Area with MODIS Satellite Image (Case Study: South Coast of West Java)
}

\author{
Dudung Muhally Hakim ${ }^{1,2}$, Ketut Wikantika ${ }^{1,2}$, Nengah Widiadnyana ${ }^{3}$, Asmi M. \\ Napitu ${ }^{4}$ \& Soni Darmawan ${ }^{2}$ \\ ${ }^{1}$ Research Group of Remote Sensing and Geographical Information Sciences \\ (KK INSIG) Faculty of Civil and Environmental Engineering - ITB, \\ ${ }^{2}$ Center of Remote Sensing - ITB, \\ ${ }^{3}$ Research Council of Marine and Fisheries, \\ Ministry of Marine Affairs and Fisheries, Republic of Indonesia. \\ ${ }^{4}$ Institute for Marine Research and Observation - Bali, \\ Ministry of Marine Affairs and Fisheries, Republic of Indonesia
}

\begin{abstract}
According to UNCLOS, Indonesian marine territorial covers an area equal to around 2.8 million square kilometers inner archipelagic seas. Though the Indonesian water region is very wide, the resource within it is not yet been exploited optimally. Indonesia still has problems that have to be copped with, including identification of marine fishing ground areas. This report proposes a technology to make the fish-catching be more efficient and effective with the help of MODIS satellite image in term of Surface Temperature and chlorophyll-a computation. Data conversion from digital number to Water Brightness Temperature are performed. The determination of potential fishing ground area were conducted based on temperature and chlorophyll-a parameters which serve as an indicator of upwelling and observations were carried out on parameters which show this phenomenon. Based on the result, during May 2004 the upwelling process were not happened yet, and it seems to occur in June 2004. It showes by the decreasing of water temperature in South Coast of West Java particularly between the border of West Java and Central of Java. This phenomenon acts as an indicator for the raising of primer productivity and will takes about one month after upwelling to the bloom of phytoplankton.
\end{abstract}

Keywords: chlorophyll-a; fishery; MODIS; SST; upwelling.

\section{$1 \quad$ Introduction}

According to United Nation Conference on the Law of the Sea [5], the Indonesian territorial water covers an area equal to around 2.8 million square kilometers inner archipelagic seas. Indonesia has also the rights to manage natural marine resources and their coherent importance in the Exclusive Economic Zone (EEZ) that have ratio 2.8 to its land mass which equal to 1.9 million square kilometers. Indonesia also entitled the right to involve in

Received April 2006, Revised September $18^{\text {th }}$ 2006, Accepted for publication September $25^{\text {th }} 2006$. 
processing and gaining benefits of international deep sea natural resources beyond the bounds of shelf continent zone.

Though the Indonesian water region is very wide, the resource within it is not yet been exploited optimally including in the case of oceanic fishery utilization. There are already lots of Indonesian experts that have been mastering marine and fishery science and technology, yet they have still facing problems that have to be copped with.

One of the main problem that have to be resolved in the utilization of oceanic fisheries resources is the hardness of finding an area which have high probability for catching fishes (fishing ground area). Fishermen tend to only use their previous knowledge based on empirical data and observations on natural signs. The unavailability of information on stocks of oceanic fisheries and lack of knowledge on fish migration cause big and unbalanced fishing efforts. This condition will threatened the long term sustainability of oceanic natural resources. Due to this reason, this report proposes a technology to make the fish-catching be more efficient and effective. One of the technologies that used is the application of MODIS satellite image to predict fishing ground areas. The expected result is to produce a fishing ground map which has high probability as medium map information for fishermen and other fishery stakeholders.

\section{Sea Surface Temperature and Chlorophyll-a from MODIS}

The procedure to derive Sea Surface Temperature (SST) and chlorophyll-a from MODIS satellite image is divided into two major steps that are pre-processing and processing. In pre-processing consisted of data and software preparation. Data was obtained from Remote Sensing Data Center of LAPAN (National Aeronautics and Aviation Agency), while the software for image processing are open source software which can be downloaded freely from internet (MODISH, 2005).

Raw MODIS satellite images used in this research covers Sumatra, Java and Kalimantan Island, while the study area only covers South Coast of West Java. Due to this reason, the image was clipped to only covers the region of interest. This process was carried out by using MRT Swath software.

Geometric correction was done by applying linear method which is included in the MRT Swath software. In this software, there was also data conversion from digital number (DN) or scale integer (SI) to Water Brightness Temperature values $(\mathrm{Tb}=$ temperature brightness) and/or reflectance. This conversion process was carried out by using equation (1). 


$$
\mathrm{R}=\mathrm{R} \_ \text {Scale }_{\mathrm{b}}\left(\mathrm{SI}_{\mathrm{b}}-\mathrm{R} \_ \text {Offset }_{\mathrm{b}}\right)
$$

where:

$R \quad=$ radiance or reflectance value,

$R \_$Scale $_{b} \quad=$ scale value in band $b$

$R \_$Offset ${ }_{b} \quad=$ R_offset value in band $b$

Hereinafter the Inverse Planck Function (Black Body Radiation) was used to derive the Water Brightness Temperature $(\mathrm{Tb})$ with an assumption of temperature of earth room chamber equal to $300^{0 \mathrm{~K}}$, which written in equation (2).

$$
T b=\frac{C_{2} V_{i}}{\ln \left(1+\left(C_{1} V_{i}^{3} / R\right)\right.}
$$

where:

$$
\begin{array}{ll}
\mathrm{Tb} & =\text { Water Brightness Temperature }\left({ }^{\mathrm{O}} \mathrm{K}\right) \\
\mathrm{C}_{1} \text { and } \mathrm{C}_{2}= & \text { constant values }\left(1.1910659 \times 10-5 \mathrm{~m}-1 \mathrm{Wsr}^{-1} \mathrm{~cm}^{4}\right. \text { and } \\
& 1.438833 \mathrm{~cm}) \\
\mathrm{V}_{\mathrm{i}} & \text { central wave number, for the band } 31 \text { is equal to } 867.302 \mathrm{~cm}^{-1} \\
& \text { and band } 32 \text { is equal to } 831.95 \mathrm{~cm}^{-1} \\
\mathrm{R} & =\text { radiance value }
\end{array}
$$

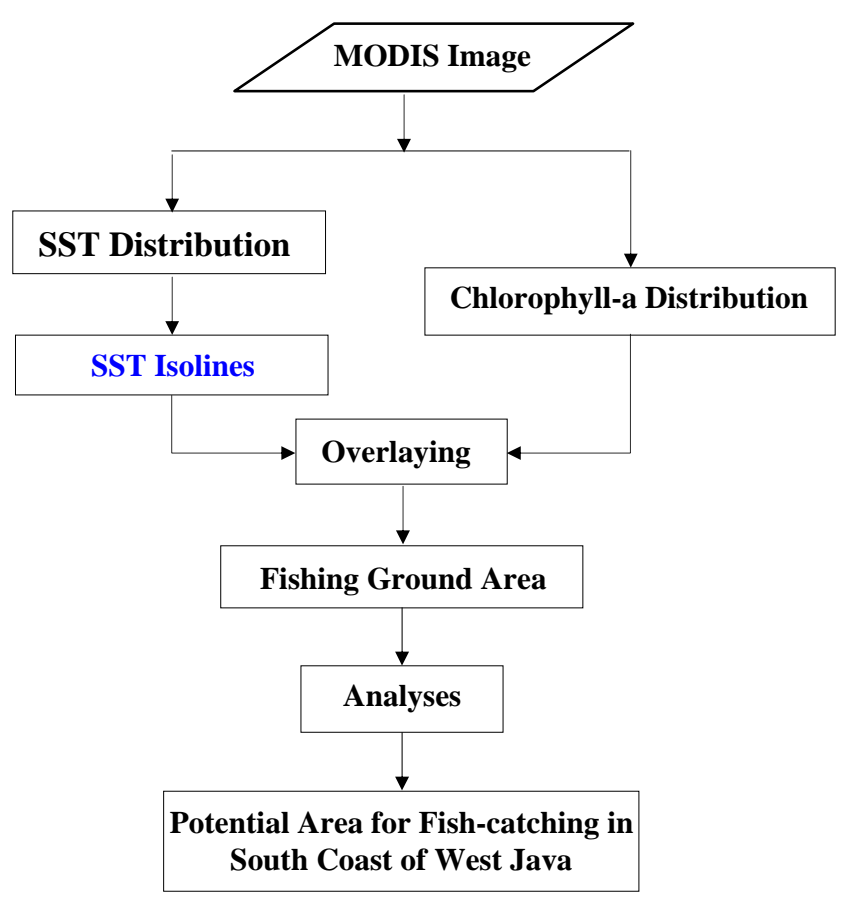

Figure 1 The flow-chart to identify fishing ground area. 
The determination of potential fishing ground area were conducted based on temperature and chlorophyll-a parameters. This matter relate to the temperature and chlorophyll-a which serve as an indicator of upwelling and generally temperature is utilized as indicator to determine ecological change.

By using the approach of upwelling and its relation with fishing ground area, observations were carried out on parameters which shows this phenomenon. A location on the sea which is suspected to be a fishing ground area must have both of these characteristics: (i) temperature gradient is more dense than its surroundings within the radius of 3 kilometers, and (ii) have high concentration of chlorophyll-a. The flow chart to identify fishing ground area is shown in Figure 1.

MODIS satellite images that have been processed to SST distribution map then were converted to isolines map with $0.5^{\circ} \mathrm{C}$ interval. With this method, by using visual method then oceanographic phenomenon will be easily observed. See Figure 2.

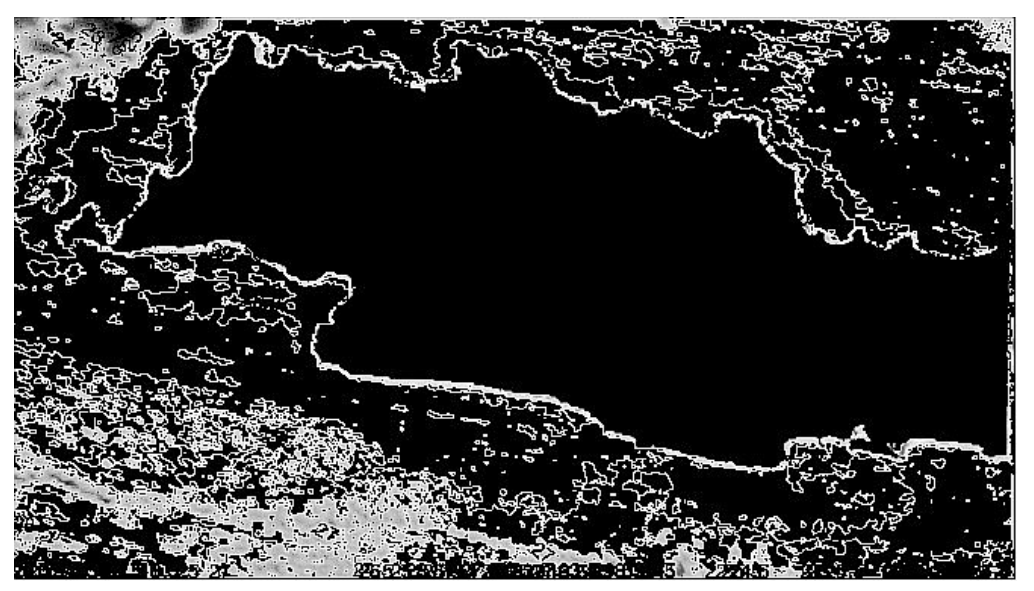

Figure 2 SST isolines map.

MODIS satellite images that have been processed to become the distribution chlorophyll-a then overlaid with the isolines SST which have been yielded from the same image. This new raster layer will show the potential fishing ground area from the closeness of temperature isolines and the high level of chlorophyll-a concentration. This mechanism is displayed in Figure 3. 


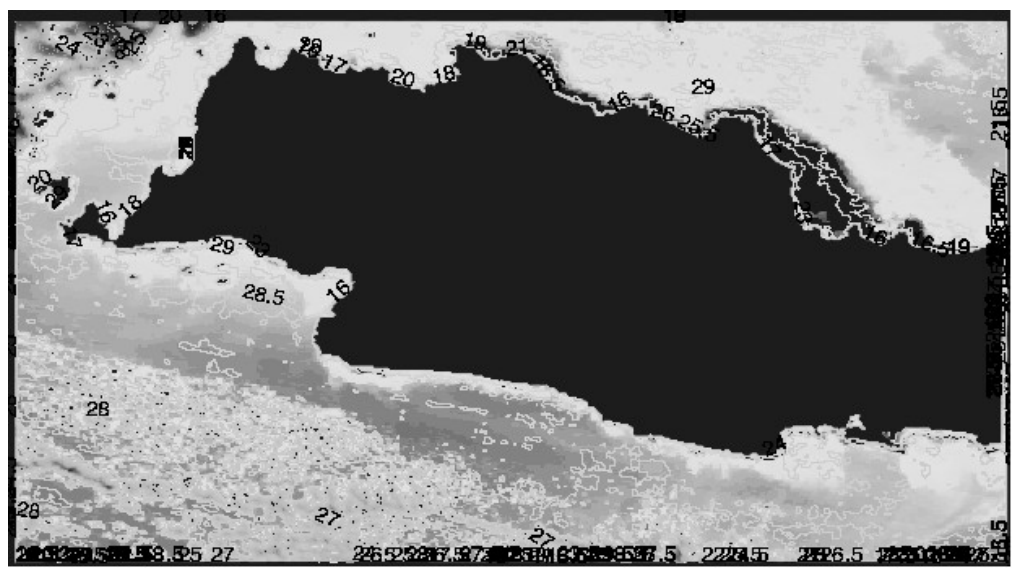

Figure 3 Overlay between SST and Chlorophyll-a.

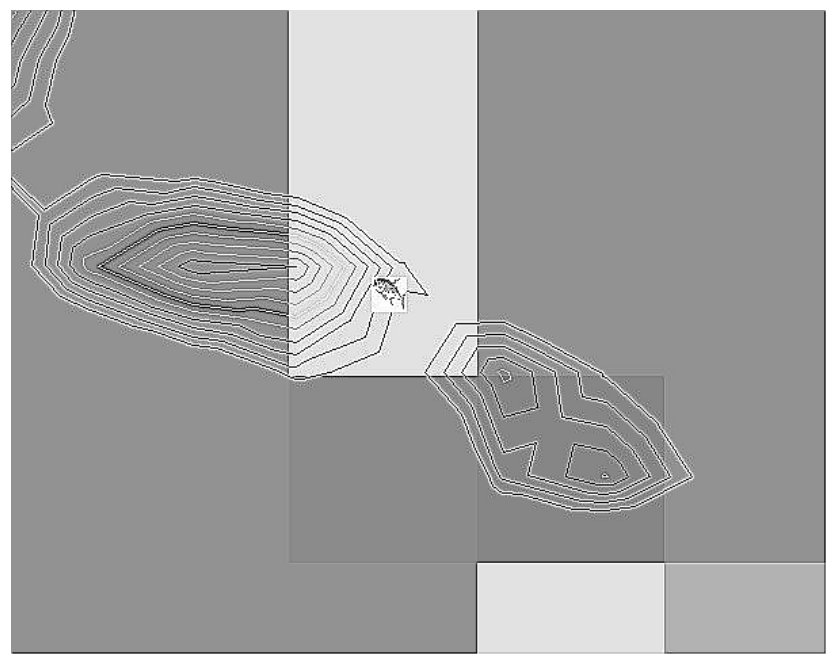

Figure 4 Potential fishing ground area.

Temperature isolines shows a location with more dense gradient than its surroundings which resembles a higher temperature by $0.5^{\circ} \mathrm{C}$ within three kilometers radius and has higher concentration of chlorophyll-a. This location is suspected to be a potential fishing ground area. See Figure 4. 


\section{$3 \quad$ Fish Abundance}

\subsection{Salinity and Temperature Measurements}

Water temperature was measured using Sea-bird CTD model SBE 19-03. This device has three sensors, i.e., temperature sensor to measure temperature, conductivity sensor to measure electrical conductivity, and pressure sensor to measure pressure of the sea.

Sea-bird CTD records temperature, electrical conductivity, and pressure data continuously as long as this device was put in the depth of the sea. Water salinity was determined by the relationship between conductivity, pressure and temperature which were gained from CTD sensors. Conversion method to receive this salinity value was develop by UNESCO in 1978, which known as Practical Salinity Scale (PSS). Temperature and salinity data were transferred from Sea-bird CTD through Seasoft CTD software. The measurement of these two parameters were carried out along the end route of acoustic tracks. See Figure 5.

\subsection{Acoustic Data Measurements}

Survey activities in the sea were carried out by using pinisi boat that build up with Simrad EY-500 Scientific Echosounder device (frequency $38 \mathrm{KHz}$ and 120 $\mathrm{Khz}$ ) and its software. This survey were begun with survey design, especially about the track design on each area to cover acoustic measurement needs.

SIMRAD EY-500 for this acoustic survey were tuned to several frequencies, $120 \mathrm{KHz}$ for depth range from 5 - 150 meters, $38 \mathrm{KHz}$ for depth range from 5 50 meters and 5 - 200 meters, TVG: 20 logarithm R and 40 logarithm R, the speed of the ship was maintained at $5.5 \sim 7$ knot, pulse length: medium, Sv Minimum: - $70 \mathrm{~dB}$ and TS minimum: - $60 \mathrm{~dB}$

Acoustic data were recorded continuously during the journey. To know the information on the existence of pelagic fishes, data were divided into back scattering cross-section for TS determination and integrator echo data to assess the absolute density.

Integrator echo method used in this research, was develop by MacLennan. The collected data were then analyzed using EP-500 software with 1 mile Elementary Sampling Distance Unit (ESDU), to assess the information on pelagic fishes density and distribution and target strength prediction. The analyzes were then validated with fishes catch by fishermen. 


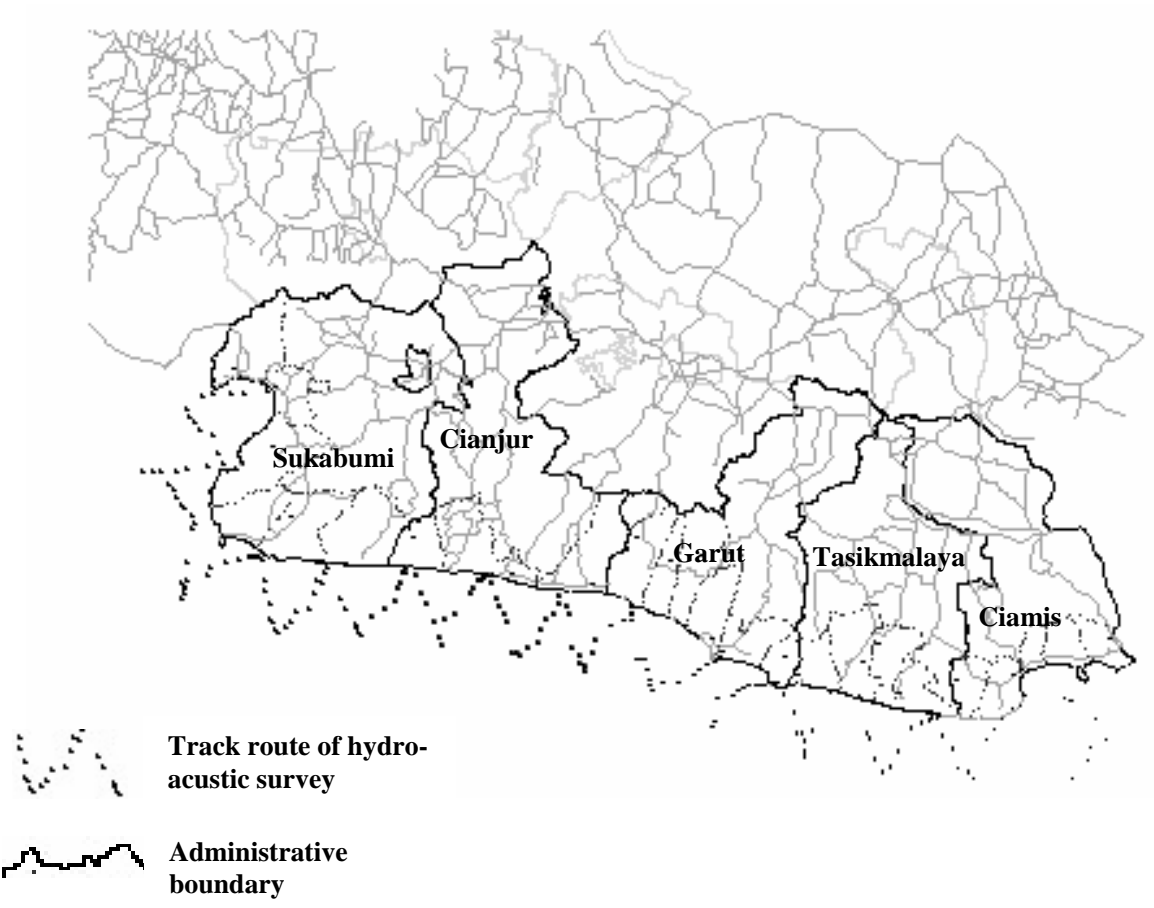

Figure 5 Track route of hydro-acoustic survey in South Coast of West Java at September 2005.

\subsection{Acoustic Data Processing and Analyzes}

Acoustic data were processed using EP-500, Microsoft Excel, Surfer and Matlab softwares. The main objective of this processing is mainly to derive target strength (TS) value and prediction on fish length, distribution and density both spatially and temporally. TS value and predicted fish length were differentiated by means of fish characteristics, i.e., fish with bladder (bladder fish) and without bladder (bladderless fish). To predict fish length ( $\mathrm{L}$ in centimeters) from TS value, this research uses empirical formulae/equation develop by Foote [1]:

$$
\begin{aligned}
& \text { TS }=20 \log \mathrm{L}-68 \text {; bladder fish } \\
& \mathrm{TS}=20 \log \mathrm{L}-78 \text {; bladderless fish }
\end{aligned}
$$

Fish density in individual per $1000 \mathrm{~m} 3$ were measured by using $S a$ value (backscattering area coefficient) and TS value with a formulae/equation develop by MacLennan \& Simmonds [3] - equations (5) \& (6): 


$$
\begin{aligned}
& \rho_{\mathrm{A}}=\mathrm{Sa} / \Sigma \mathrm{fi} \bullet \sigma_{\mathrm{bs}} \\
& \sigma_{\mathrm{B}}=10^{T S / 10}
\end{aligned}
$$

where area density for each size group of fishes are - equation (7):

$$
\rho_{i}=f i \bullet \rho_{A}
$$

and then the volume density were measured by using this algorithm as written below in equation (8):

$$
\rho_{V}=\rho_{A} \bullet\left(\mathrm{r}_{2}-\mathrm{r}_{1}\right)
$$

The grouping on fish density from hydro-acoustic data were based on TS interval, large pelagic fish range from $-45 \mathrm{~dB}$ to $-27 \mathrm{~dB}$ and small pelagic fish from $-60 \mathrm{~dB}$ to $-42 \mathrm{~dB}$.

\section{$4 \quad$ Result and Discussion}

This research use ten (10) MODIS satellite images that resemble the phenomenon which happened in one year period. Figure 6 shows the result of processed MODIS image as SST and chlorophyll-a. From these images, it is clear that during May 2004 the upwelling process were not happened yet. This phenomenon seems to occur in June 2004, which was showed by the decreasing of water temperature in South Coast of West Java especially between the border of West Java and Central of Java. The occurrence of upwelling was not followed immediately by the increase of chlorophyll-a concentration. This phenomenon acts as an indicator for the raising of primer productivity. It takes about one month after upwelling to the bloom of phytoplankton.

The one month interval period was used by the algae to reproduce themselves in a high nutrient condition. This is showed by the MODIS processed image where in June 2004, the upwelling process started but there was no increase in chlorophyll-a concentration and started to increase in July 2004. Upwelling process occurs in July until September which showed by the decrease of SST in South Coast of West Java. The temperature starts to increase again in November until April next year. 


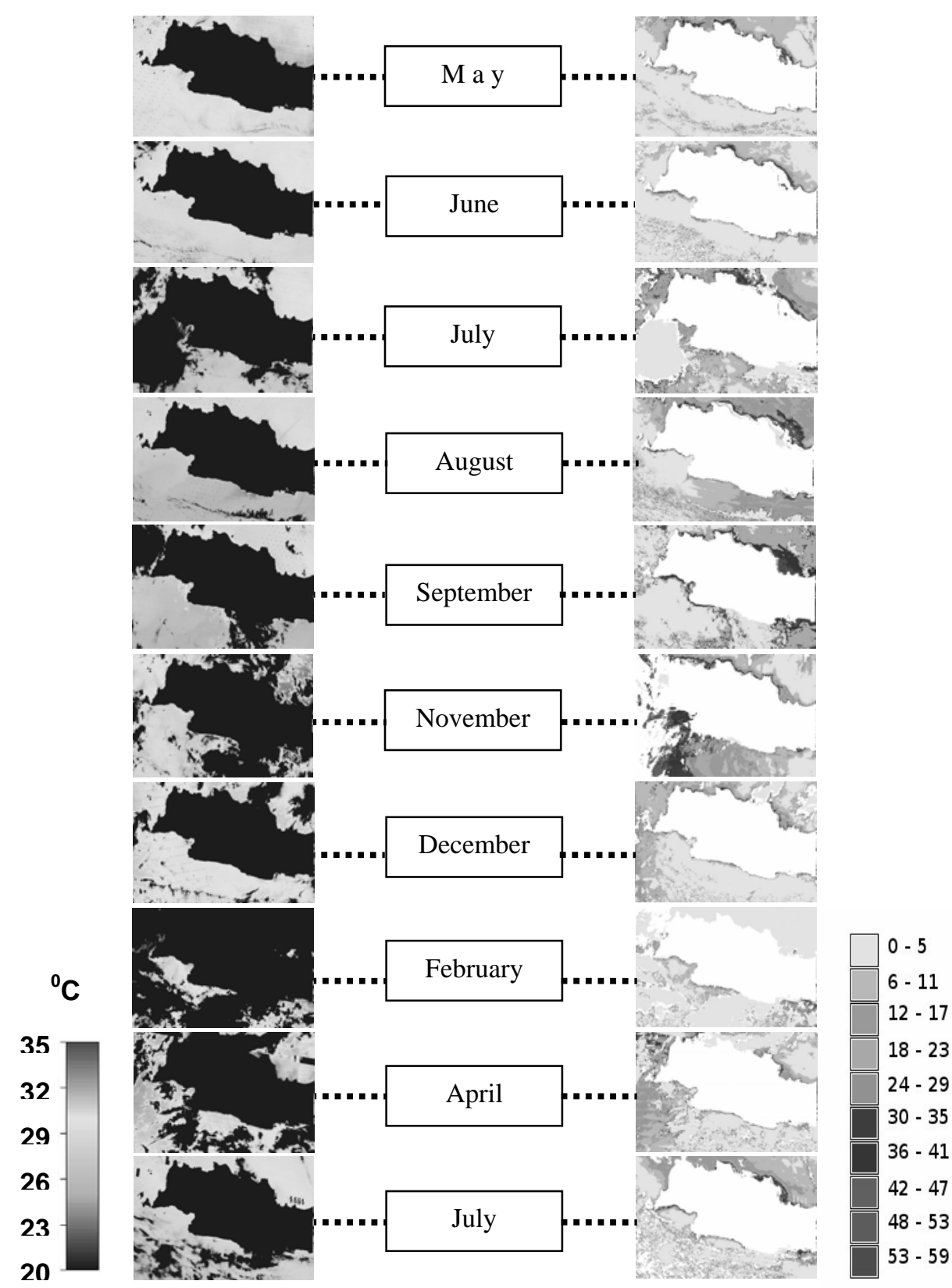

Figure 6 Distribution map of SST and chlorophyll-a (May 2004 - July 2005). 


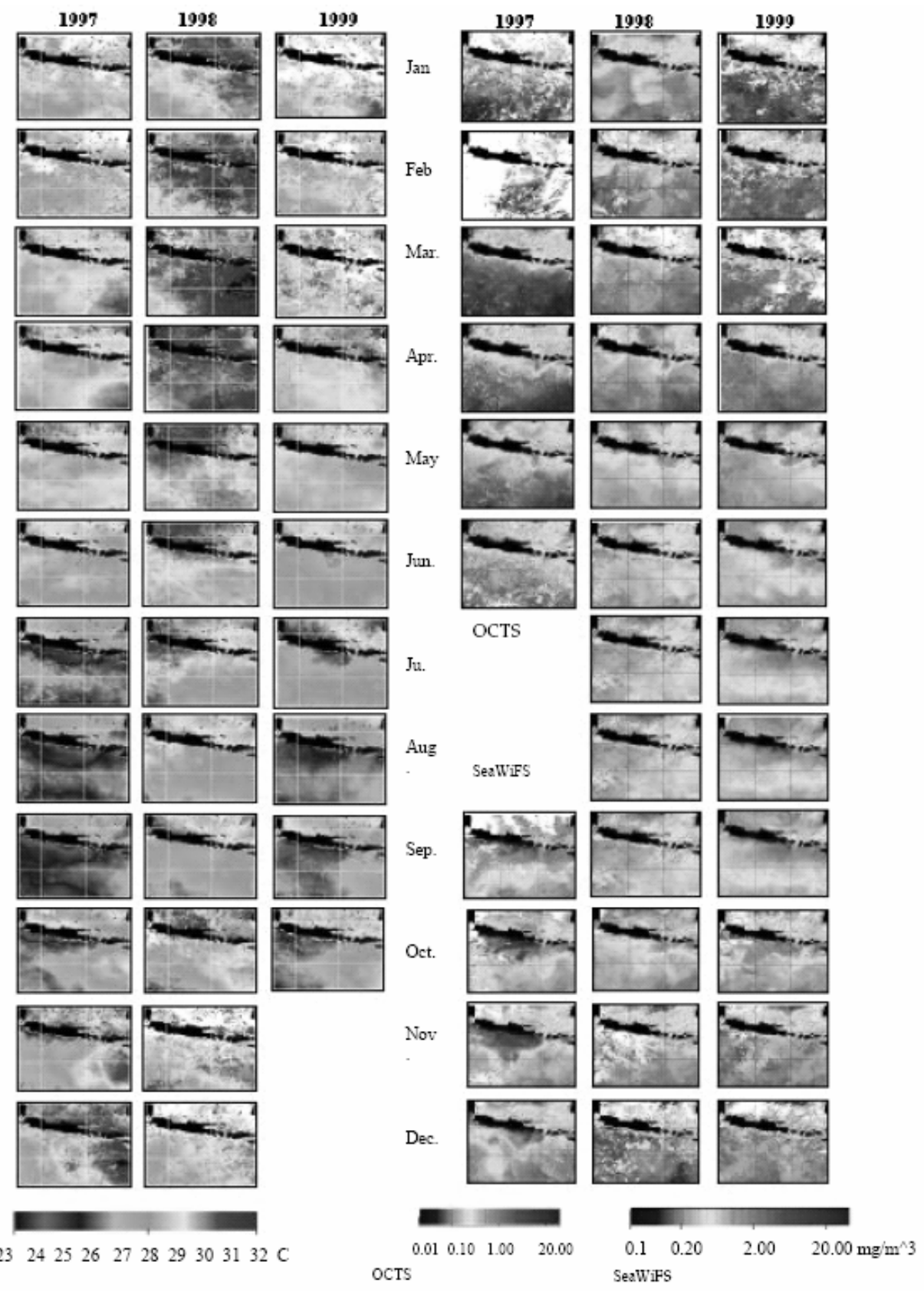

Figure 7 Distribution map of SST and chlorophyll-a (1997-1999). [2] 
Figure 7 shows distribution pattern of SST and chlorophyll-a in the area of south coast of Island of Java during the period of 1997-1999. This figure reveals the same pattern with the research result, the difference between them is the intensity of the upwelling process. This might be due to other oceanographic phenomenon like El-Nino in the year of 1997.

\section{$5 \quad$ Conclusion}

In this report, it has been investigated the application of MODIS satellite image to predict fishing ground areas. Based on the result, it comes to some conclusions that are:

MODIS satellite image as one of the remote sensing application is very potential to be utilized in predicting fishing ground area. The measurement on the images of May 2004 until July 2005 shows the capability of MODIS satellite images to extract SST and chlorophyll-a parameters. These are useful to identify the time and position of upwelling process.

The result shows that the upwelling process in South Coast of West Java starts in the month of July. Primer productivity which served as an indicator of upwelling process starts to occur in one month period after the occurrence of upwelling.

Based on the measurement on MODIS images, the upwelling process starts from the border of West Java and Central of Java (Ciamis). This indication is proven by the relatively high fish abundance than other areas in South Coast of West Java.

\section{Acknowledgement}

We would like to thank LPPM ITB for the funding of this investigation, and also to LAPAN for the immediate response when we were looking for getting MODIS image.

\section{Reference}

[1] Foote, K.G., On Representing the Length Dependence of Acoustics Target Strength of Fish, J. Fish. Res. Bd. Can., 36: 1940 - 1946 (1979).

[2] Gaol, Lumban, J., Mahapatra, K., Okada, Y., Pasaribu, B.P., Manurung, D., \& Nurjaya, I.W., PORSEC 2002 BALI Proceedings, Fish Catch Relative to environmental Parameters Observed from Satellite During ENSO and Dipole Mode Events 1997/98 in the South Java Sea (2002). 
[3] MacLennan, D.N. \& Simmonds, J.E., Fisheries Acoustics, Chapman \& Hall, London, England (1992).

[4] MODIS, Swath Reprojection Tool (MRT Swath) distribution page, http://edcdaac.usgs.gov/landdaac/tools/mrtswath/ (1995).

[5] UNCLOS, Indonesia,http://www.apec-oceans.org/ economy\%20profile\% 20summaries/indonesia-approved.pdf\#search=\%22UNCLOS\%201982\% 20Indonesia \%22 (1983). 